\title{
Moral distress and compassion fatigue in nurses of neonatal intensive care unit
}

\author{
Zahra Noghanchi Saleh ${ }^{1}$, Laleh Loghmani ${ }^{2}$, Maryam Rasouli ${ }^{3}$, Maliheh Nasiri ${ }^{4}$, Fariba Borhani ${ }^{5}$
}

\begin{abstract}
Background: Nurses working in neonatal intensive care units are increasingly faced with a moral distress due to nature of their profession. It is anticipated that this amount of moral distress can have a negative effect on their affection and compassion towards the patient. The aim of this study was to determine the correlation between moral distress and compassion fatigue in NICU Nurses.

Method: This descriptive correlational study was conducted with 172 nurses working in the neonatal intensive care unit in educational hospitals in 2016. Data were collected using demographic information form, Corley's moral distress questionnaire, Figley's compassion fatigue. Data were analyzed by descriptive and inferential statistical tests.

Findings: The mean score of moral distress in the range (0-5) in the repetition dimension was $0.62 \pm 2.01$ and in the dimension of intensity was 0.89 \pm 3.11 . The average of compassion fatigue in the range (0-6) was $0.50 \pm 3.94$, normal to high. In examining the dimensions of compassion fatigue, the highest score belonged to the degree of compassion satisfaction $0.82 \pm 4.48$ and then the exhaustion $0.53 \pm 3.70$ and post-traumatic stress $0.84 \pm$ 3.63 .

Conclusion: The results of this study indicated that there was a significant positive correlation between the intensity of moral distress and compassion fatigue ( $P=0.001 r=0.436)$, but between the frequency of moral distress and compassion fatigue, there was no relationship ( $P=0.142 r=0.137)$. Significant correlation was found between age $(r=0.22)$, nursing experience $(r=0.24)$ and work experience in neonatal intensive care unit $(r=0.187)$ with compassion fatigue. The results of this study indicate that extreme moral distress can be related with compassion fatigue.
\end{abstract}

Keywords: moral distress, compassion fatigue, NICU nurse

\section{INTRODUCTION}

Moral distress impedes the proper moral performance of individuals despite having knowledge (1). Jamton expresses the moral distress in terms that you know what the right thing is, but organizational constraints make it impossible to follow up or do the right thing. Moral distress can be originated from nursing empathic care from the patient (2). Moral distress leads to negative effects such as sadness, anxiety, feeling of disapproval, dissatisfaction, occupational burnout, and the desire to leave a job or work place and cause negative outcomes for some patients, such as poor quality of care $(3,18)$.

One of the possible consequences of moral distress is the caring person's fatigue to compassion for the patients (19). Compassion fatigue undermines the quality of care, and therefore, health organizations must identify related factors and find solutions to prevent and resolve (22).

\footnotetext{
1 Master Student in Neonatal Intensive Care, Student Research Committee, International Branch, ,School of Nursing Midwifery, Shahid Beheshti University of Medical Sciences, Tehran, Iran.

2 Assistant Professor, School of Nursing and Midwifery, Bam University of Medical Sciences, Bam, Iran.

3 Associate Professor, Department of Pediatrics, School of Nursing Midwifery, Shahid Beheshti University of Medical Sciences, Tehran, Iran.

${ }^{4}$ Assistant Professor, Department of Biostatistics, School of Nursing Midwifery, Shahid Beheshti University of Medical Sciences, Tehran, Iran.

5 Associate Professor, Department of Medical - Surgical Nursing, School of Nursing Midwifery, Medical Ethics and Law Research Center, Shahid Beheshti University of Medical Sciences, Tehran, Iran.
}

Correspondence: Fariba Borhani

Associate Professor, Department of Medical - Surgical Nursing, School of Nursing Midwifery, Medical Ethics and Law Research Center, Shahid Beheshti University of Medical Sciences, Tehran, Iran

E-mail: faribaborhani@msn.com

Received: 20 Feb 2018, Accepted: 10 May 2018

(C) 2019 by the authors; licensee Modestum Ltd., UK. This article is an open access article distributed under the terms and conditions of the Creative Commons Attribution License (http://creativecommons.org/licenses/by/4.0/). 
Table 1: Correlation between the frequency score and intensity of moral distress with the scores of compassion fatigue dimensions in nurses

\begin{tabular}{|c|c|c|c|c|c|}
\hline \multirow{2}{*}{ Compassion Fatigue Dimensions } & \multirow{2}{*}{$\begin{array}{c}\text { Mean } \\
0-6\end{array}$} & \multicolumn{2}{|c|}{$\begin{array}{c}\text { Frequency of Moral Distress } \\
\text { Mean } 2.01(0-6)\end{array}$} & \multicolumn{2}{|c|}{$\begin{array}{c}\text { Intensity of Moral Distress } \\
\text { Mean } 3.11(0-6)\end{array}$} \\
\hline & & $\begin{array}{l}\text { Pearson Correlation } \\
\text { Coefficient }\end{array}$ & P-Value & $\begin{array}{l}\text { Pearson Correlation } \\
\text { Coefficient }\end{array}$ & P-Value \\
\hline Compassion Satisfaction & 4.48 & 0.002 & 0.975 & 0.288 & 0.001 \\
\hline Exhaustion & 3.7 & 0.092 & 0.326 & 0.181 & 0.052 \\
\hline Post-Traumatic Stress & 3.63 & 0.190 & 0.041 & 0.389 & 0.001 \\
\hline Total Score of Compassion Fatigue & 3.94 & 0.137 & 0.142 & 0.436 & 0.001 \\
\hline
\end{tabular}

The causes of moral distress in the NICU are numerous. Factors such as the need for communication between the parents and the treatment team and the professional relationship between the care and treatment teams. In addition, the forced use of invasive methods in dying infants, the pain and suffering caused by invasive diagnostic and therapeutic methods, several experiments, the need for trained personnel, and the use of technology make the nurses of this section exposed to high levels. Due to the difficulty and sensitivity work, the issue of moral distress and compassion fatigue in this section will be prioritized. However, the conducted studies in this section are very limited compared to the emergency, oncology and specialist parts of adults (4).

Studies have been done on the moral distress in Iran. In addition, the study of the relationship between moral distress and compassion fatigue has been done in Kerman on ICU nurses (20). However, the study of each of these variables and the relationship between these two variables has not been done in the NICU nurses' community. The purpose of this study was to investigate the correlation between moral distress and compassion fatigue in NICU nurses of selected educational hospitals in Tehran in 2016, considering the importance of the issue of moral distress and compassion fatigue and the effects that may affect the quality and quantity and cost of provided care.

\section{METHOD}

The present study is a descriptive-correlational study. In this study, were entered into by objective and available sampling method 172 NICU nurses of selected hospitals who had the criteria for entering the research and were satisfied to complete the questionnaire. For collecting data, the Persian version of Corley's moral distress questionnaire and Figley's compassion fatigue were used.

The distress questionnaire has 30 questions that each phrase refers to a specific situation in hospital care. The perception of people investigated from both aspects of the intensity of moral distress and the abundance of situations in which a person is confronted with distress. Compassion fatigue questionnaire has 30 phrases in three items. The lowest score is 30 and the highest score is 180 .

The time required to complete each questionnaire was approximately 15 to 20 minutes. Nurses were reminded that there was no need to mention the name on the questionnaires. Data were analyzed using SPSS 16 software. For descriptive statistics were used frequency distribution tables, mean and standard deviation. Pearson correlation statistical tests were used for analyzing the relationships between variables, according to the normal distribution of data, independent $t$ and analysis of one-way ANOVA at a significant level of 0.05 .

\section{RESEARCH FINDINGS}

According to Table 1, the mean frequency and intensity of moral distress in the nurses were respectively 2.01 (average) and 3.11 (high). The mean score of compassion fatigue was 3.94. The mean of fatigue scores in different dimensions and its correlation with the frequency and intensity of moral distress is shown in Table 1.

There was a significant correlation between compassion satisfaction and age $(p=0.001)$. There was a significant correlation between the mean of total compassion fatigue with age $(p=0.003)$. There was a significant correlation between compassion satisfaction and post-traumatic stress with work experience and between total score of compassion fatigue with work experience. There was a significant correlation between total score of compassion fatigue and work experience in neonatal intensive care unit $(p=0.041)$. In other words, with increasing work experience of NICU nurses' compassion fatigue was increased in them. There was no significant difference between single and married subjects in terms of the frequency and intensity of moral distress and there is not scores for compassion fatigue dimensions. Only satisfaction of compassion was significant among single and marital subjects $(P=0.039)$ in means that compassion satisfaction in married people was more than unmarried. 


\section{DISCUSSION AND CONCLUSION}

The average intensity of moral distress in nurses was 3.11. If we assume the range of possible intensity between zero and five, the average result of intensity examination of moral distress in nurses will be high range. Most studies have reported this intensity of moral distress in nurses a lot. 3.80 of nurses in the critical segment and $65 \%$ of nurses in the intensive care unit reported that, exposed to a lot of moral distress (21). Mohammadi et al. (20) reported this about 3.5. Borhani et al. (5) reported the intensity of moral distress among nurses of Birjand educational hospitals 2.25 in average. The average intensity of moral distress in nurses working in educational hospitals of Jiroft is reported to be 3.4. In the ICU nurses of Hamedan, the intensity of moral distress in the range of 0 to 216, was 99.34 (6). Therefore, it seems that, moral distress issue must be at the center of the attention for managers to take action.

Mean frequency of moral distress in NICU nurses in this study was 2.01. It can be considered as moderate. This rate has been set at nurses of Sirjan 1.5 (7), in Kerman 3.9 (20), and in nurses of Birjand 2.11. (5). Since the abundance of moral distress is highly dependent on the environment and type of nursing work, it can be expected to see a difference in terms of sections, hospitals, cities, and even type of work in one section.

The compassion fatigue score in nurses is 3.94. This rate is moderate to high and indicates that nurses in the neonate sector experienced a relatively large proportion of this problem in their work environment. Borhani et al. (8) reported this rate in nurses working in teaching hospitals of Kerman 3.53, which is less than this study. The stressful nature of the NICU due to the vulnerability of infants, the response of nurses to the infant's parents, the high mortality rate and the possibility of unnecessary care in this unit can be a possible cause of this difference $(18,22)$. Among the factors of compassion fatigue questionnaire, the highest score belongs to compassion satisfaction (4.48) and the lowest is related to post-traumatic stress (3.63), and the burnout factor with a slight difference located between these two. (3.7). High level of compassion satisfaction indicates the emotional relationship of the nurse and the patient in the community, which is compassion for the patient's health problems. These results indicate that nurses in these sections should be especially familiar with the ways of communicate with patients, especially newborns, and needed for training and planning to enhance the nurses' ability in this field.

The relationship between compassion fatigues with moral distress in this study showed that compassion fatigue has a significant positive correlation with intensity of distress. In other words, the frequency of relationship between distress and compassion fatigue is not significant, but there is a meaningful relationship with intensity of distress. This suggests that the abundance of moral distress cannot lead to compassion fatigue if it is well managed. However, if moral distress is understood for any reason strongly, the chances of compassion fatigue increase or that, those who are tired of compassion are more likely to understand the intensity of moral distress. These results indicate that nurses in these sections should be especially familiar with the ways of to communicate with patients, especially newborns, and needed for training and planning to enhance the nurses' ability in this field (4).

As the conclusion, it can be said that the average of moral distress and compassion fatigue does not indicate the suitability of the situation. It is also alarm for managers to take action. On the other hand, a significant relationship between the intensity of moral distress and the compassion fatigue shows that each of these two can be prioritized, and reduction of each one can led to another's decrease.

\section{ACKNOWLEDGEMENT}

This article is the result of the Master's Thesis of NICU Nursing the International Branch of the Faculty of Nursing and Midwifery of Shahid Beheshti University of Medical Sciences. Thanks to the honorable professors, all the authorities, and the nurses who helped us with this research, we have the best regards.

\section{REFERENCES}

1. Nejadsarvari N, Abbasi M, Borhani F, Ebrahimi A, Rasooli H, Kalantar Motamedi MH, ... Bazmi S. Relationship of Moral Sensitivity and Distress among Physicians. Trauma Monthly. 2015;20(2):e26075.

2. Schluter J, Winch S, Holzhauser K, Henderson A. Nurses' moral sensitivity and hospital ethical climate: A literature review. Nursing Ethics. 2008;15(3):21-304. https://doi.org/10.1177/0969733007088357

3. Abbasi M, Nejadsarvari N, Kiani M, Borhani F, Bazmi S, Nazari Tavaokkoli S, Rasouli H. Moral Distress in Physicians Practicing in Hospitals Affiliated to Medical Sciences Universities. Iranian Red Crescent Medical Journal. 2014;16(10):e18797. https://doi.org/10.5812/ircmj.18797 
4. Sannino P, Gianni ML, Re LG, Lusignani M. Moral distress in the neonatal intensive care unit: an Italian study. J Perinatol. 2015;35(3):7-214. https://doi.org/10.1038/jp.2014.182

5. Borhani F, Abbaszadeh A, Nakhaee N, Roshanzadeh M. The relationship between moral distress, professional stress, and intent to stay in the nursing profession. Journal of Medical Ethics and History of Medicine. 2014;7:3.

6. BeykMoradi A, Rabiee S, Khatibian M, Cheraghi MA. Moral distress in ICU nurses: Survey Study in Hamedan Educational and Therapeutic Hospitals. Iranian Journal of Ethics and Medical History. 2012;5(2):58-69.

7. Abbas ZA, Nakhai N, Borhani F, Roshanzadeh M. Moral distress in clinical function of nurses: A descriptive-cross sectional study. Journal of Medical Ethics. 2012;6(23):113-130.

8. Borhani F, Mohammadi S, Roshanzadeh M. Moral distress and perception of futile care in intensive care nurses. Journal of Medical Ethics and History of Medicine. 2015;8:2.

9. Adams RE, Boscarino JA, Figley CR. Compassion fatigue and psychological distress among social workers: a validation study. American Journal of Orthopsychiatry. 2006;76(1):103. https://doi.org/10.1037/00029432.76.1.103

10. Corley MC. Nurse moral distress: a proposed theory and research agenda. Nursing ethics. 2002;9(6):50-636. https://doi.org/10.1191/0969733002ne557oa

11. Elpern EH, Covert B, Kleinpell R. Moral distress of staff nurses in a medical intensive care unit. American Journal of Critical Care. 2005;14(6):30-523.

12. Figley CR. Compassion fatigue: Psychotherapists' chronic lack of self-care. Journal of clinical psychology. 2002;58(11):41-1433. https://doi.org/10.1002/jclp.10090

13. Janvier A, Nadeau S, Deschenes M, Couture E, Barrington KJ. Moral distress in the neonatal intensive care unit: caregiver's experience. J Perinatol. 2007;27(4):8-203. https://doi.org/10.1038/sj.jp.7211658

14. Larazian JJ, Whitt-Woosley A. Compassion fatigue, compassion satisfaction, and burnout: Factors impacting a professional's quality of life. Journal of Loss and Trauma. 2012;12(3):80-259.

15. Meyer RM, Li A, Klaristenfeld J, Gold Jl. Pediatric novice nurses: examining compassion fatigue as a mediator between stress exposure and compassion satisfaction, burnout, and job satisfaction. Journal of pediatric nursing. 2015;30(1):83-174. https://doi.org/10.1016/j.pedn.2013.12.008

16. Peter E, Liaschenko J. Perils of proximity: a spatiotemporal analysis of moral distress and moral ambiguity. Nursing inquiry. 2004;11(4):25-218. https://doi.org/10.1111/j.1440-1800.2004.00236.x

17. Rice EM, Rady MY, Hamrick A, Verheijde JL, Pendergast DK. Determinants of moral distress in medical and surgical nurses at an adult acute tertiary care hospital. Journal of nursing management. 2008;16(3):73-360. https://doi.org/10.1111/j.1365-2834.2007.00798.x

18. Cavaliere TA, Daly B, Dowling D, Montgomery K. Moral distress in neonatal intensive care unit RNs. Adv Neonatal Care. 2010 Jun;10(3):145-56.

19. Adams RE, Boscarino JA, Figley CR. Compassion fatigue and psychological distress among social workers: a validation study. American Journal of Orthopsychiatry. 2006;76(1):103.

20. Somayeh Mohammadi, Fariba Borhani, Leili Roshanzadeh, Mostafa Roshanzadeh .Moral distress and compassion fatigue in patient care: a correlational study on nurses.2014,7(2).69-79.Iranian Journal of Medical Ethics and History of Medicin

21. Mason, Virginia M. PhD, RN, ACNS-BC, CCRN; Leslie, Gail MSN, RN, PMHCNS-BC; Clark, Kathleen BSN, RN, MMHC; Lyons, Pat MS, RN, CNS-BC, CCRN, CPAN; Walke, Erica MSN, ACCNS-AG, RN; Butler, Christina BSN, RN; Griffin, Martha PhD, RN, FAAN.2014.Compassion Fatigue, Moral Distress, and Work Engagement in Surgical Intensive Care Unit Trauma Nurses: A Pilot Study.Dimension of critical care nursing. 2018,37,4,235-236.

22. Brown, K. W., \& Ryan, R. M. (2003). The benefits of being present: Mindfulness and its role in psychological wellbeing. Journal of Personality and Social Psychology, 84(4), 822-848. https://doi.org/10.1037/0022-3514.84.4.822

$\diamond \diamond \diamond \diamond \diamond \diamond \diamond$

http://www.ejgm.co.uk 